\title{
Assessing the genetic structure of capercaillie (Tetrao urogallus) in Romania
}

\author{
Mihai Fedorca ${ }^{1,2}$, Ovidiu Ionescu1,2, Neculae Sofletea ${ }^{2}$, Ancuța Fedorca1,2, Alexandru \\ Lucian Curtur ${ }^{2}$, Georgeta Ionescu ${ }^{\circledR}$
}

Fedorca M., Ionescu O., Șofletea N., Fedorca A., Curtu A.L., Ionescu G., 2020. Assessing the genetic structure of capercaillie (Tetrao urogallus) in Romania. Ann. For. Res. 63(2): 15-26.

Abstract Romania holds the most extensive mountain range with oldgrowth forests, in which both habitat surface and capercaillie (Tetrao urogallus) numbers are ones of the highest in Central and Eastern Europe. While previous genetic studies have found that the individuals located in different European mountain ranges are isolated and have highlighted that the species is declining. Here, we are aiming to assess the genetic structure of capercaillie in Romania by genotyping 137 samples collected in the field with 9 STR markers. Expected heterozygosity was 0.586 , whereas observed heterozygosity values were 0.859 . Population structure analyses indicated weak population differentiation and suggested that sufficient gene flow exists among individuals sampled in different mountain regions. We did not find evidence for a past genetic bottleneck. Our findings contain important information to wildlife managers to focus conservation efforts in areas such as Curvature Carpathians, which serve as a connectivity corridor to avoid eroding the extent or quality of habitat and to prevent further fragmentation.

Keywords: capercaillie, genetics, gene flow, fragmentation, habitat

Addresses: ${ }^{1}$ National Institute for Research and Development in Forestry "Marin Dracea", SCDEP Brasov, $\left.\right|^{2}$ Transilvania University of Brasov, Romania $\rightleftarrows$ Corresponding author: Georgeta Ionescu (titi@icaswildlife.ro).

Manuscript received September 22, 2020; revised November 3, 2020; accepted December 10, 2020. 


\section{Introduction}

The risk of extinction on the long-term can be evaluated by studying a population's genetic diversity reduction, by the presence of inbreeding, or by the reduction of the response capacity for environmental changes (Keller \& Waller 2002, Tallmon et al. 2004, Segelbacher et al. 2008, Cazacu et al. 2014). If different populations remain connected, e.g. due to the dispersal of individuals, and in some cases it has been shown that one migrant per generations may be enough (Mills \& Allendorf 1996, Wang 2004), to maintain gene flow and thus keep genetic diversity preserved (Segelbacher \& Storch 2002). The spatial distribution and genetic structure of some populations can be influenced by the dispersal of some individuals which is also the case of capercaillie showing no genetic evidence of sex-biased dispersal and could easily benefit from that rule of one migrant per generation (Mäki-Petäys et al. 2007).

In Central Europe, and not only, the capercaillie is also considered as an umbrella species regarding the conservation of mountain forest ecosystems (Storch 1993, Straupe et al. 2019). Capercaillie is a species which is spread across Europe, mainly in the northern countries and Russia (Regnaut 2004). The Carpathians are Europe's largest mountain range (Gurung et al. 2009), and most of the old-growth forests of Europe can be found there (Grodzińska et al. 2004, Mikolas et al. 2015). 52.9\% of the total range of the Carpathians is located in Romania (Grodzińska et al. 2004). The status of the species in Europe is Least Concern (BirdLife International 2015) and in Romania is listed as a game species, but without a hunting period, which gives the specie a protection status. Thus, knowledge of the genetic substructure of the species is crucial for the species' management.

In Romania, both the habitat and the population numbers (between 2200 and 2400 calling/leking males) are one of the highest in Central and Eastern Europe (BirdLife International 2015). Even though there have been conducted numerous studies on this species in Europe, the information regarding the population from Romania is lacking sti11, and, only small subpopulations have been studied, or few samples have been used (Segelbacher \& Piertney 2007, Klinga et al. 2015). Recent studies have suggested that the species is declining (Segelbacher et al. 2003, Bajc et al. 2011), and that individuals from different mountain ranges seem isolated from each other. However, a targeted study to study and evaluate the situation in Romania, has been so far lacking. Furthermore, a specifically targeted, genetic assessment combining size and fragmentation status of the habitat, to guide the management of this species can potentially predict if population numbers and connectivity may be stable on the long-them (Lencinas et al. 2018, Vallant et al. 2018). Assessing the population status of elusive species, like the capercaillie, can be challenging (Aleix-Mata et al. 2019), especially when the data set and sample numbers remain limited (Augustine et al. 2019).

The migration of individuals (dispersal $=$ the movement of individual organisms from their natal area to other locations for breeding (Greenwood \& Harvey 1982) or gene flow = the transfer of genes from one area to another by dispersal and successful reproduction (Slatkin 1985) is affected by the habitat and its change under the influence of the anthropic factors, with direct consequences for the long term conservation of the species. For a better understanding on the effect ofthese factors, it is needed to associate individual genetic information with individual geographic distances (i.e., sampling locations) (Peakall et al. 2003).

The goal of this study was to assess the genetic structure of capercaillie in Romania. We used non-invasive samples collected to identify the number of subpopulations located and to identify potential corridors of 
connectivity and dispersal.

\section{Materials and methods}

\section{Study area and sample collection}

In the period 2013-2015, we collected noninvasively 138 capercaillie samples (faeces) from 7 different mountain ranges across Romania, after identification in the field, every sample was stored in a plastic vial, filled with alcohol, and kept at room temperature in the laboratory, until the analyses. Also, the location of the sample, using a GPS-unit was recorded. The samples were collected in the spring season and, however, we took only single faeces from a lek, during the collection process to avoid doubling the samples. In 2013 we collected samples from Suceava (6), Mureș (11) and Harghita (11), in 2014 from Neamț (34) and Curvature Carpathians (7) and in 2015 from Făgăraș (21) and Retezat (47) (Figure 1).

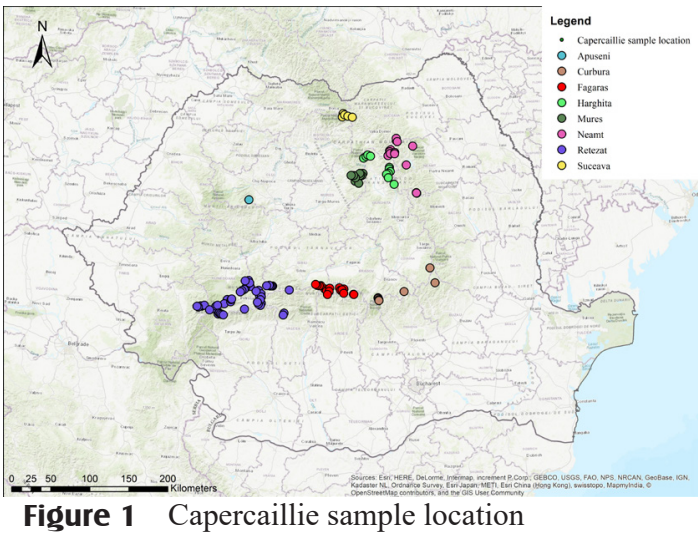

Genetic analyses

DNA was isolated in our laboratory, using an automated DNA extractor (Maxwell 16 from Promega); and we used $1 \mathrm{ml}$ of the ethanol from the vial where the faeces sample was stored according to an optimized protocol (Fedorca et al. 2018). Seven microsatellite loci, described for capercaillie (TUD7, TUT4, TUD8, TUD3, TUT1, TUT2 and TUD6)
(Segelbacher et al. 2000) and two described for black grouse were used (BG15 and BG18) (Piertney and Hoglund 2001), was divided into two multiplexes (multiplex 1: BG15, TUT2, TUT1, TUT4) and multiplex 2: TUD3, TUD6, BG18, TUD7, TUD8). PCR reactions were performed in $15 \mu \mathrm{l}$ mixture, containing $7.5 \mu \mathrm{l}$ of Qiagen Multiplex PCR Kit, $2 \mu$ of DNA and fluorescently labelled markers (concentration depending on each marker). Fragment analysis was performed in a mixture of $40 \mu \mathrm{l}$ consisting of SLS, Size Standard and PCR product, using the FRAG-3 method on the GenomeLab ${ }^{\mathrm{TM}}$ GeXP Genetic Analysis System. Alleles were scored using GenomeLab ${ }^{\mathrm{TM}}$ Software (Beckman Coulter, Inc).

\section{Statistical analysis}

\section{Quality assurance}

A first step in the analyses of the database consisted in testing for null alleles. This analysis was conducted using MICROCHECKER software (Van Oosterhout et al. 2004), no evidence for allele dropout or null alleles were found for the analysed set of markers.

\section{Genetic structure}

For testing the population genetic structure and possible spatial genetic discontinuity were implemented in software STRUCTURE v 2.3.4 (Pritchard et al. 2000, Evanno et al. 2005) and GENELAND v 4.03 (R package) (Guillot 2005, Guillot et al. 2012) applying the Bayesian algorithm Markov Chain Monte Carlo (MCMC). The stochastic model for STRUCTURE v 2.3.4. consisted in setting the number of iterations to 5 , for each number of expected subpopulations $(\mathrm{K}), \mathrm{K}=1$ to 10 , and $500.000 \mathrm{MCMC}$ repetitions, after 1 million simulations. In order to estimate the posterior probability of appearance of a certain number of subpopulations, we used the $\operatorname{Ln}(\mathrm{K})$ 
value given by the STRUCTURE software, and $\Delta K$ was calculated (Evanno et al. 2005). In GENELAND (Guillot 2005, Guillot et al. 2012) software were implemented 100.000 iterations with a narrow of 100 (1000 iterations have been saved), for $K=1$ to 10 subpopulations. The repetitions have been conducted including also the geographic position of all the analysed samples. Additionally, for determining population structuring we used TESS software (Chen et al. 2007), choosing values from $\mathrm{K}=2$ to 10 , for each subpopulation five repetitions, were conducted using 1.200 simulations with 200 repetitions.

\section{Genetic diversity}

In order to see if the genotypes are distributed randomly in the study area or if they show a genetic structure determined by a high level of relatedness, we used spatial autocorrelation analyses and the relatedness coefficient $r$ (Smouse et al. 2008), and the software GenAlex v 6.5 (Peakall \& Smouse 2012). We used two different tests in order to determine the differences between the relatedness coefficient of a null model (9999 random permutation of all the genotypes in space) and all the observed genotypes between given distances. In order to determine the unique genotypes of the class distances, we calculated the median coordinates of the multiple geographic positions (Rösner et al. 2014).

Both $\mathrm{F}_{\text {st }}$ and FIS indices (Hartl \& Grant, 1997, Rousset 1997) were calculated using FSTAT v 2.9.3.2 software (Goudet 1995), in order to determine the level of differentiation. In order to test if the Romanian capercaillie population have passed recently through a genetic bottleneck, we used the software BOTTLENECK v 1.2.02 (Piry et al. 1999), with the Wilcoxon test and IAM and S.M.M. model of determining mutations, using 9999 iterations (Cornuet \& Luikart 1996).

Nei genetic distance is closely correlated/ influenced by the private alleles (are alleles that are found only in a single population among a broader collection of populations) found in the chosen subpopulations. This distance has a maximum value when each of the subpopulations has a different allele. In order to determine Nei genetic distance, GeneAlEx software has been used.

To estimate the relation between the genotype and the distance among the samples we have used the GenAlEx software (Peakall $\&$ Smouse 2012). This software calculates the multilocus autocorrelation coefficient $r$ between the genotypes of the individuals which are between certain distance classes, having values between 1 and -1 , and a confidence interval of $95 \%$ (Neville et al. 2006).

In order to test the spatial autocorrelation between samples, we have used distance classes of $60 \mathrm{~km}$ in each interval, in which, 60 $\mathrm{km}$ being less than the maxim dispersal rate of an individual (Segelbacher 2002).

\section{Results}

\section{Genetic structure}

The sex of the individuals was determined in our laboratory according to the faeces size (Jacob et al. 2010) and the majority were males, further differentiated sex analyses were not implemented.

For determining the number of capercaillie subpopulations, the whole results from STRUCTURE were analyzed using STRUCTURE HARVESTER. However, our hypotheses for $\mathrm{K}=2$ (Figure 3, a), 3 (Figure 3, c), 4 (Figure 3, d), or more have not been supported by STRUCTURE HARVESTER (Figure 2, a) and TESS results (Figure 2, b and Figure 3, b). Further, GENELAND analysis indicated the presence of 4 subpopulations (Figure 2, c), but this have not been supported by the spatial analysis (Figure 4).

For a better understanding of the results, we have used GIS software to plot the genetic clusters obtained from STRUCTURE on a map using the location of the samples, and for TESS and GENELAND software (Figure 4). The results 
from TESS are similar with the results from STRUCTURE, showing that the capercaillie population is not subdivided, and the GENELAND results which show a possibility of the capercaillie to be divided into 4 subpopulations.

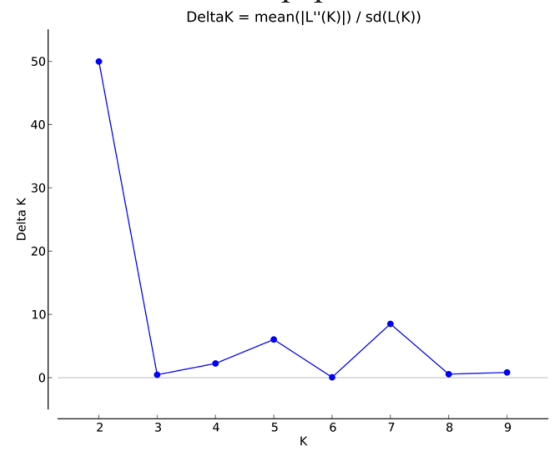

(a)

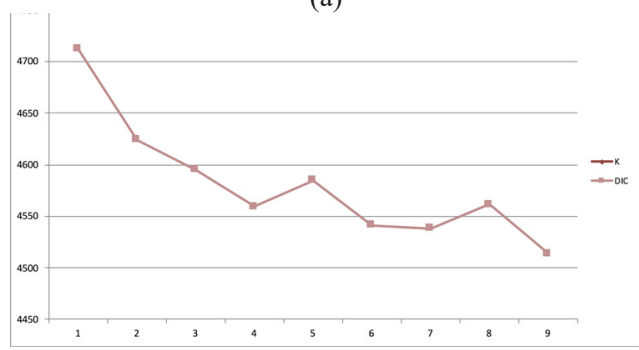

(b)

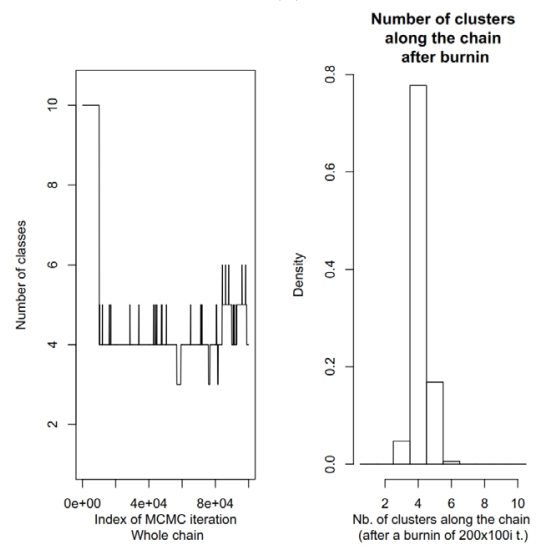

(c)

Figure 2 (a) $\Delta K$ values resulted from STRUCTURE software; (b) $\mathrm{K}$ values resulted from TESS with the vertical axis representing the DIC values, and the horizontal axis representing the number of clusters ( $\mathrm{K}$ max); (c) Index of MCMC iteration whole chain from GENELAND software and number of clusters.

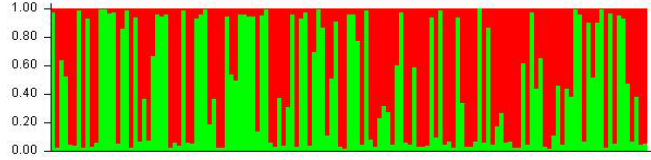

(a)

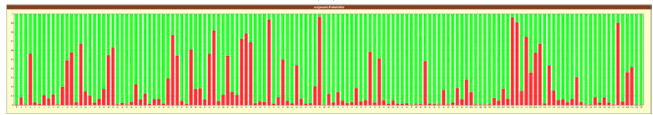

(b)

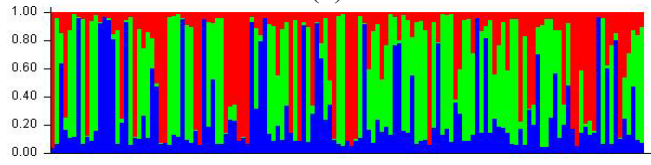

(c)

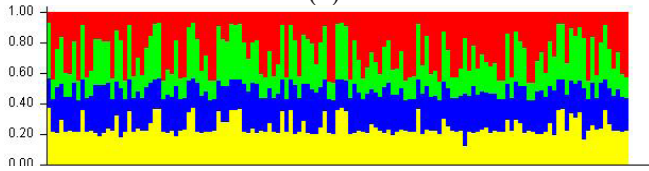

(d)

Figure 3 Genetic structure of capercaillie revealed by nine microsatellite markers; Bayesian histogram for $\mathrm{K}=2$, without LOCPRIOR with the genotypes sorted per area from STRUCTURE (a), histogram resulted from TESS software $\mathrm{K}=2$ (b), Bayesian histogram for $\mathrm{K}=3$, without LOCPRIOR with the genotypes sorted per area from STRUCTURE (c) and Bayesian histogram for $\mathrm{K}=4$, withoutLOCPRIOR with the genotypes sorted per area from STRUCTURE (d).

\section{Genetic diversity}

Regarding the number of alleles/locus (Table 1), the highest value was observed at TUD6 marker $(\mathrm{Na}=9)$ while the mean value for this parameter at all the analysed marker was $\mathrm{Na}=4.89$.

The overall observed heterozygosity was $\mathrm{Ho}=0.859$, the highest value of the observed heterozygosity was registered by TUT2 marker $(\mathrm{Ho}=0.985)$, while the smallest value was registered by TUT4 marker $(\mathrm{Ho}=0.484)$. The mean expected heterozygosity was $\mathrm{He}=0.58$, with the highest value registered by the marker TUD $6(\mathrm{He}=0.778)$.

Allelic richness was calculated for the entire population $(\mathrm{AR}=2.8)$, the highest value was registered 
by the TUD6 marker (4.44) while the smallest for the TUD7 and TUT2 markers (2.0) (Table 2).

The results from the genetic distances Nei indicated that the highest distance is between the individuals located in Harghita Mountains and the ones located in Curvature Carpathians (0.121), followed by the ones located Neamt, and Curvature Carpathians (0.102). The smallest values have been registered between Făgăraș and Retezat Mountains (0.007). When

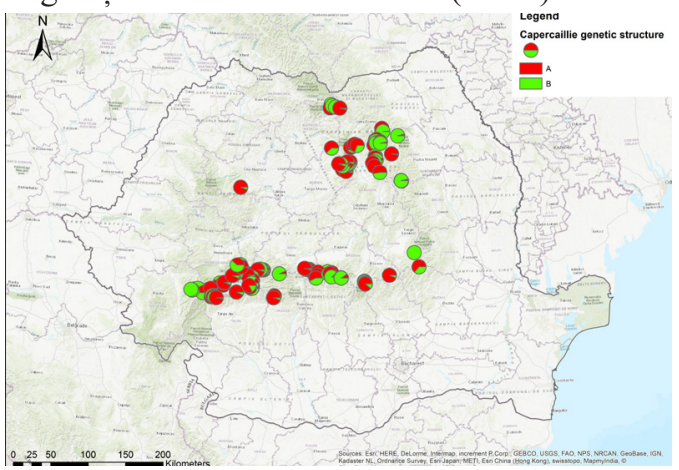

(a)

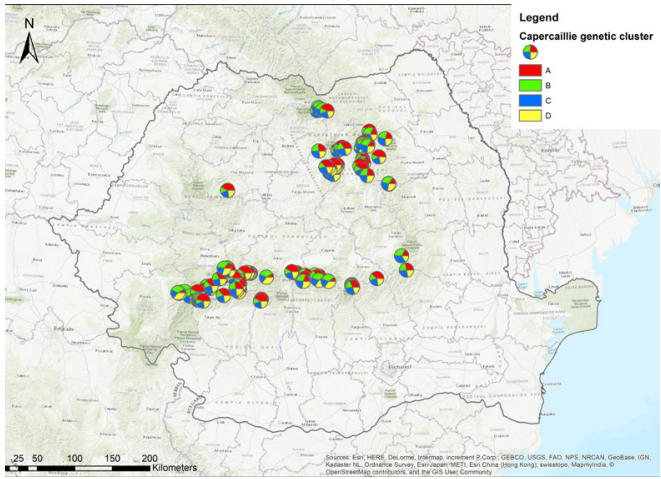

(b)

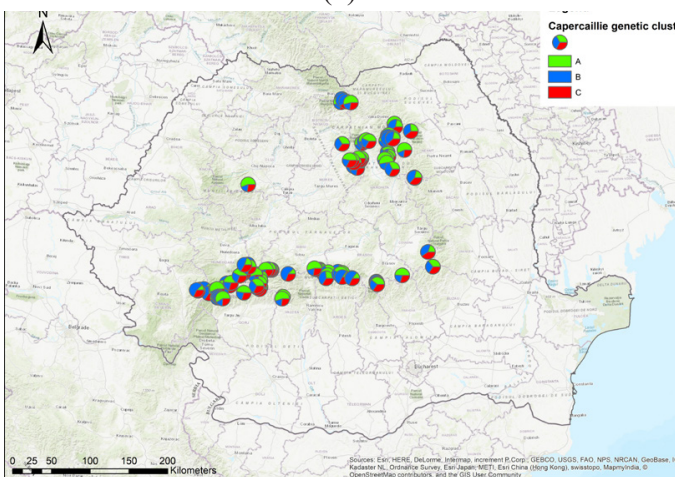

(c) calculating the Nei genetic distances between Southern Carpathians and Eastern Romanian Carpathians, the results indicated a very close genetic structure $(\mathrm{Nei}=0.015)$. Furthermore, after visualizing these results on dendrograms, the results showed that the Curvature Carpathians are differentiated in a single class with a small distance from the other mountain ranges (Figure 5).

In order to test if the individuals located in different mountain ranges are grouped in different genetic structures, the results showed that the Romanian capercaillie population is not isolated by distance, the p-value $=0.509$. However, in order to see the differences between the mountain ranges we used $F_{\text {st }}$ values (Table 3 ).

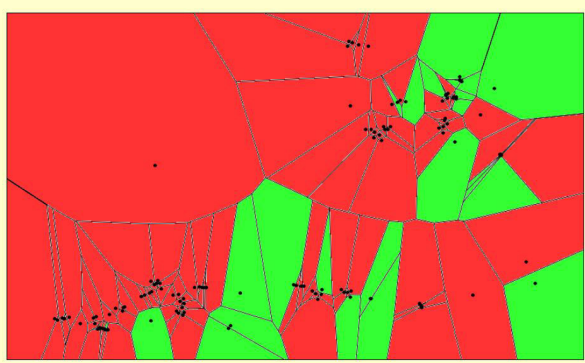

d)

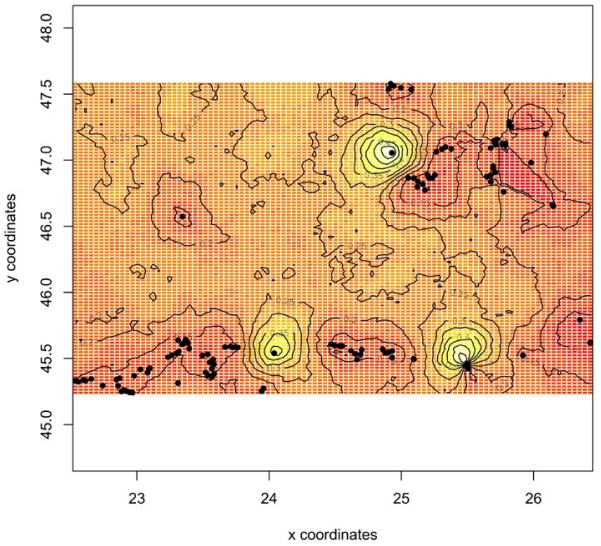

(e)

Figure 4 Distribution of genetic cluster using STRUCTURE (a) - K=2; b) - K=3; c) $\mathrm{K}=4$ ), TESS(d) and GENLAND (e) 


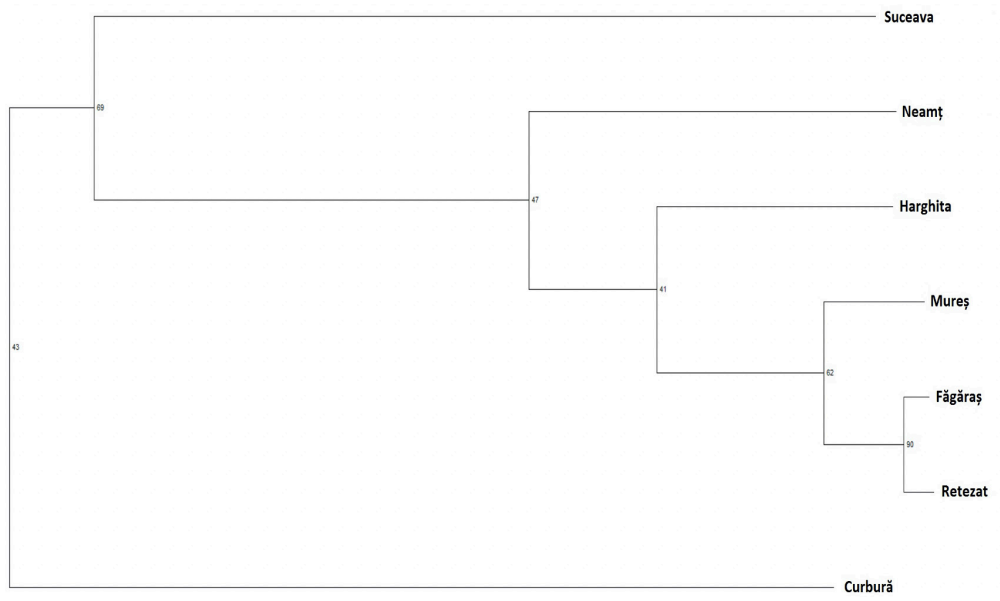

Figure 5

UPGMA (unweighted pair group method with arithmetic mean) dendrogram for the capercaillie subpopulations.

Table 1 Genetic parameters of capercaillie for the entire Romanian population calculated with GenAlEx software

\begin{tabular}{lrrrrrr}
\hline Locus & AR & Na & Ne & Ho & He & F \\
\hline TUD7 & 2.00 & 2 & 2.000 & 0.970 & 0.500 & -0.941 \\
TUT4 & 3.19 & 5 & 2.137 & 0.484 & 0.532 & 0.091 \\
TUD8 & 2.03 & 3 & 2.027 & 0.955 & 0.507 & -0.884 \\
BG15 & 2.19 & 5 & 2.080 & 0.913 & 0.519 & -0.759 \\
TUD3 & 3.25 & 5 & 3.153 & 0.908 & 0.683 & -0.329 \\
TUT1 & 3.08 & 7 & 2.655 & 0.946 & 0.623 & -0.517 \\
TUT2 & 2.00 & 2 & 2.000 & 0.985 & 0.500 & -0.970 \\
BG18 & 2.99 & 6 & 2.713 & 0.926 & 0.631 & -0.466 \\
TUD6 & 4.44 & 9 & 4.499 & 0.643 & 0.778 & 0.173 \\
\hline Average & 2.80 & 4.889 & 2.585 & 0.859 & 0.586 & -0.511 \\
\hline
\end{tabular}

AR - allelic richness, $\mathrm{Na}$ - number of alleles per locus, $\mathrm{Ne}$ - effective number of alleles, Ho - observed heterozygosity, $\mathrm{He}$ - expected heterozygosity, $\mathrm{F}$ - fixation index

Table 2 Allelic richness (AR) of capercaillie per population/subpopulation and per locus resulted from FSTAT software

\begin{tabular}{lrrrrrrrr}
\hline Locus & Romania & Suceava & Neamț & Harghita & Mureș & Curvature & Făgăraș & Retezat \\
\hline TUD7 & 2.00 & 2.00 & 2.00 & 2.00 & 2.00 & 2.00 & 2.00 & 2.00 \\
TUT4 & 3.19 & 3.00 & 1.54 & 3.16 & 3.09 & 4.94 & 3.38 & 3.23 \\
TUD8 & 2.03 & 2.00 & 2.00 & 2.00 & 2.00 & 2.00 & 2.00 & 2.21 \\
BG15 & 2.19 & 2.00 & 2.00 & 2.45 & 2.56 & 2.00 & 2.00 & 2.32 \\
TUD3 & 3.25 & 3.00 & 3.58 & 2.93 & 2.93 & 3.67 & 3.38 & 3.26 \\
TUT1 & 3.08 & 3.00 & 2.82 & 2.85 & 2.95 & 3.82 & 2.91 & 3.21 \\
TUT2 & 2.00 & 2.00 & 2.00 & 2.00 & 2.00 & 2.00 & 2.00 & 2.00 \\
BG18 & 2.99 & 3.00 & 4.05 & 2.71 & 2.50 & 2.93 & 2.85 & 2.89 \\
TUD6 & 4.44 & 4.00 & 5.07 & 4.92 & 4.09 & 4.00 & 4.73 & 4.28 \\
\hline Total & 2.80 & 2.67 & 2.78 & 2.78 & 2.68 & 3.04 & 2.80 & 2.82 \\
\hline
\end{tabular}




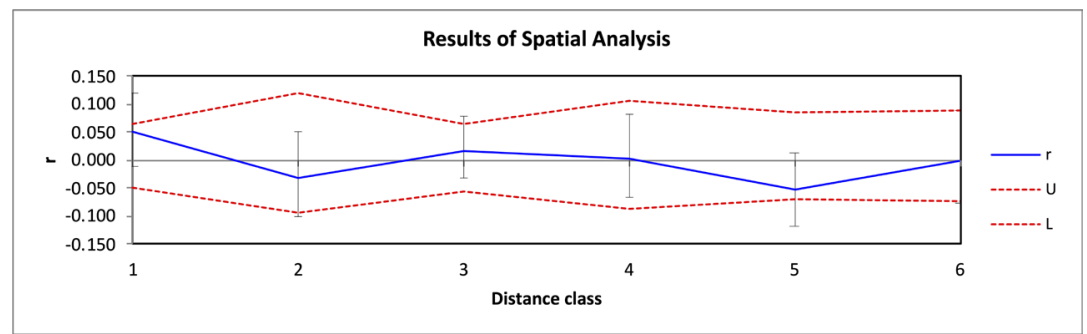

Figure 6 Correlogram (GenAlEx) showing pairwise genetic relatedness of capercaillie, using six equal distance classes, $r$ - correlation coefficient, $r$ is the coefficient of similarity among the individual genotypes within a distance class (solid line). Bootstrap error bars are also shown for each distance class. The red dotted lines ( $\mathrm{U}$ and $\mathrm{L}$ ) represent the upper and lower confidence intervals for the null hypothesis (no autocorrelation among the genotypes within the distance classes $(r=0)$.

The results for the two tests (SPM and ModeShift) indicated that capercaillie population had not passed recently through a bottleneck effect (Table 4), moreover, the results obtained from the pairwise genetic relatedness were not significant (Figure 6).

Table $3 \quad \mathrm{~F}_{\text {st }}$ values among subpopulations of capercaillie calculated with GENEPOP software

\begin{tabular}{lrrrrrr}
\hline Subpopulation & Suceava & Neamț & Harghita & Mureș & Curvature & Făgăraș \\
\hline Neamț & 0.0479 & & & & & \\
Harghita & 0.0210 & 0.0181 & & & & \\
Mureș & 0.0056 & 0.0138 & -0.0098 & & & \\
Curvature & 0.0126 & $\mathbf{0 . 0 5 5 4}$ & 0.0388 & 0.0265 & & \\
Făgăraș & 0.0039 & 0.0280 & 0.0077 & -0.0092 & 0.0020 & \\
Retezat & 0.0030 & 0.0238 & 0.0132 & -0.0053 & 0.0040 & -0.0047 \\
\hline
\end{tabular}

Table 4 Bottleneck effect testing for the entire population of capercaillie

\begin{tabular}{lrr}
\hline Probability & SPM & Mode-Shift \\
\hline Standardized differences test & 0.21771 & 0.068 \\
Wilcoxon Test & 0.32617 & \\
Sign Test & 0.36339 & \\
\hline
\end{tabular}

\section{Discussion}

Using three different genetic approaches, we were able to determine the number of subpopulations of capercaillie in Romania.

Furthermore, we found evidence that the Curvature Carpathians act as a connectivity bridge between the capercaillie population across the country, and by maintaining the capercaillie habitat in these regions, we can ensure the gene flow among the subpopulations.

Because of the STRUCTURE software which not reliably recover the correct population structure when sampling is uneven (Puechmaille 2016, Janes et al. 2017), we also compared the results obtained by STRUCTURE with the ones resulted from TESS and GENELAN. STRUCTURE and TESS results indicated that the genetic clusters are not divided between mountain ranges, suggesting that the Romanian capercaillie population is not genetically isolated and the gene flow is still ongoing. However, the GENELAND results should be interpreted with caution; samples collected from capercaillie leks, where the majority of the males are related (Regnaut et al. 2006), could bias the software's results by suggesting the presence of family structuring among them (Segelbacher - personal comments) and also because this computer software tends to overestimate genetic structure (Frantz et al. 2009).

The autocorrelation interval has not been passed; a fact can be attributed to the maxim distance that the capercaillie could travel (70 
$\mathrm{km}$ according to Segelbacher 2002), which is larger than the interval considered within this study. Overall, the results indicated that capercaillie population from Romania is panmictic (Kimura \& Weiss 1964).

Regarding the number of alleles/locus $(\mathrm{Na}=4.89)$, the value obtained by us is higher than $\mathrm{Na}=2.85$ resulted from a capercaillie study in Spain (Rodríguez-Muñoz et al. 2007), and also higher with $7.7 \%(\mathrm{Na}=4.54)$ than all the European capercaillie populations (excepting Spain) (Segelbacher et al. 2003).

The observed heterozygosity $(\mathrm{Ho}=0.859)$ registered higher values than the ones obtained for other capercaillie populations: like $\mathrm{Ho}=0.66$ in Germany and Italy (Segelbacher et al., 2003); $\mathrm{Ho}=0.72 / 0.71$ in Northern and Southern Alps (Rodríguez-Muñoz et al. 2007); and much bigger than the ones in Spain $(\mathrm{Ho}=0.44)$ (Alda et al. 2011). However, the high values of the observed heterozygosity and $\mathrm{F}$ negative values suggests the selection in favour of heterozygotes. These results are different from other studies which show that the breeding system of this species can lead to an increase of inbreeding potential because only a small proportion of the males transmit their genes (Segelbacher et al. 2007). We assume that our results can be attributed to the dominant males culling during the breeding season, which facilitated the participation in matting of more individuals, ensuring thus a permanent gene flow. This was confirmed by species behaviour in Pyrenees, where each year has registered a reorganisation of the territory of males (Catusse 1993).

Regarding the expected heterozygosity, our values are similar with the Bavarian Alps calculated by Segelbacher et al. (2003) $(\mathrm{He}=0.59-0.66)$ and higher than the one obtained by Rodríguez-Muñoz et al. (2007), for some areas from Cantabrian Mountains $(\mathrm{He}=0.36)$, where the populations are small and isolated and exhibit inbreeding effect (Alda et al. 2011).

Some authors assimilate the heterozygote excess with population decline (Cornuet \& Luikart 1996, Segelbacher 2002) while considering that there is a need for a certain number of individuals in order to preserve the genetic diversity (Soulé 1987). In fragmented habitats it is still uncertain how individuals could move between the patches (Cushman et al. 2006, Segelbacher et al. 2008); however, that is not applicable in the Romanian capercaillie population, which is a continuous one, and the habitat is unfragmented.

Compared with other studies conducted in Europe, the value of allelic richness was smaller than the ones obtained for Black Forest $(\mathrm{AR}=4.35) \quad$ (Segelbacher et al. 2008) and Poland (AR=4.075) (Rutkowski et al. 2005), and approximately equal with Jura Mountains $(\mathrm{AR}=2.78)$ (Regnaut et al. 2006). However, lower values were registered by capercaillie in the Cantabrian Mountains (Rodríguez-Muñoz et al. 2007).

Taking into consideration the $\mathrm{F}_{\text {st }}$ values, we can assume that the genetic differences between the mountain ranges are very small (Rutkowski et al. 2005), the one exception is Curvature Carpathians and Neamt area of Eastern Romanian Carpathians, the $\mathrm{F}_{\text {st }}$ value is 0.0554, indicating a small genetic differentiation (Hartl \& Grant 1997, Segelbacher 2002), which also indicated that the higher pairwise Fst-values is not in relation with the distance between subpopulations. The Fst value calculated between the biggest mountain ranges in Romania (Eastern Romanian Carpathians and Southern Carpathians) suggest a very small differentiation among the individuals from the two areas $\left(\mathrm{F}_{\mathrm{st}}=0.0064\right)$.

Even though our study assesses the capercaillie population from all the mountain ranges in Romania, the number of samples is not very high, also mitochondrial analyses could be applied. We intend to analyse the capercaillie population using a higher set of markers on a bigger set of samples and also utilising complex analyses. 


\section{Conclusion}

Our study highlighted that the capercaillie population from Romania is genetically not subdivided, and gene flow among individuals from the different regions appears sufficient. Another very important aspect regarding the genetic status of the population is, that it has not recently passed through a genetic bottleneck, furthermore, random mating within the population occurs.

Taking into consideration that capercaillie inhabits most of the mountain ranges in Romania, and its characteristic to cover a variety of habitats, from old forest, to pastures and young forests, require protection of such areas inhabited by the species, which will conserve and protect other habitats and species of high ecological value but which received less attention from both general public and decision makers, simultaneously.

\section{Acknowledgements}

We are thankful to Petre Gărgărea and the entire team from RNP Romsilva who helped us to collect the capercaillie faeces.

\section{References}

Alda F., Sastre P., De La Cruz-Cardiel P.J., Doadrio I., 2011. Population genetics of the endangered Cantabrian capercaillie in northern Spain. Animal Conservation 14:249-260. https://doi.org/10.1111/j.14691795.2010.00425.x.

Augustine B.C., Kéry M., Olano Marin J., Mollet P., Pasinelli G., Sutherland C., 2019. Sex-specific population dynamics and demography of capercaillie (Tetrao urogallus L.) in a patchy environment. Population Ecology 62:80-90. https://doi. org/10.1002/1438-390X.12031.

Bajc M., Čas M., Ballian D., Kunovac S., Zubić G., Grubešić M., Zhelev P., Paule L., Grebenc T., Kraigher H., 2011. Genetic differentiation of the Western Capercaillie highlights the importance of South-Eastern Europe for understanding the species phylogeography. PloSone 6:1-15. https://doi.org/10.1371/journal. pone. 0023602 .

BirdLife International, 2015. Tetrao urogallus
(Western Capercaillie) European Red List of Birds Supplementary Material. European Red List of Birds, Luxembourg: Office for Official Publications of the European Communities 11.

Catusse M., 1993. Spatial and temporal plasticity of a capercaillie (Tetrao urogallus) arena in the French Pyrenees. Ethology Ecology \& Evolution 5:145-156, https://doi.org/10.1080/08927014.1993.9523098.

Cazacu C., Adamescu M.C., Ionescu O., Ionescu G., Jurj R., Popa M., Cazacu R., Cotovelea A., 2014. Mapping trends of large and medium size carnivores of conservation interest in Romania. Annals of Forest Research 57:97-107. https://doi.org/10.15287/ afr.2014.170.

Chen C., Durand E., Forbes F., François O., 2007. Bayesian clustering algorithms ascertaining spatial population structure: A new computer program and a comparison study. Molecular Ecology Notes 7:747-756. https://doi. org/10.1111/j.1471-8286.2007.01769.x.

Cornuet J.Ma., Luikart, G., 1996. Description and power analysis of two tests for detecting recent population bottlenecks from allele frequency data. Genetics 144:2001-2014.

Cushman S.A., McKelvey K.S., Hayden J., Schwartz M.K., 2006. Gene flow in complex landscapes: testing multiple hypotheses with causal modeling. Wildlife Biology Faculty Publications 168:486-499. https://doi. org/10.1086/506976.

Evanno G., Regnaut S., Goudet, J., 2005. Detecting the number of clusters of individuals using the software STRUCTURE: A simulation study. Molecular Ecology 14:2611-2620. https://doi.org/10.1111/j.1365294X.2005.02553.x.

Fedorca M., Ionescu G., Ciocirlan E., Șofletea N., Fedorca A., 2020. A simple automated approach to obtain DNA from capercaillie, brown bear and wolf faeces. Conservation Genetics Resources 12:33-36. https://doi. org/10.1007/s12686-018-1061-9.

Frantz A.C., Cellina S., Krier A., Schley L., Burke T., 2009. Using spatial Bayesian methods to determine the genetic structure of a continuously distributed population: clusters or isolation by distance? Journal of Applied Ecology 46:493-505. https://doi. org/10.1111/j.1365-2664.2008.01606.x.

Gaël A., Begoña A., Mathieu B., Evelyn M., Pierre M., Gregory T., Nicolas T., Marc Mo., Jesús M. P. , Antonio S., 2019. Comparing methods for estimating the abundance of Western Capercaillie Tetrao urogallus males in Pyrenean leks: singing counts versus genetic analysis of non-invasive samples. BirdStudy 66:565569. https://doi: 10.1080/00063657.2020.1720594.

Goudet J., 1995. FSTAT (Version 1.2): A Computer program to calculate f-statistics. Journal of Heredity 86:485-486. https://doi.org/10.1093/jhered/esh074.

Greenwood P.J., Harvey P.H., 1982. The natal and breeding dispersal of birds. Annual review of ecology and systematics. 13:1-21. https://doi.org/10.1146/ 
annurev.es.13.110182.000245.

Grodzińska K., Godzik B., Frạczek W., Badea O., Oszlányi J., Postelnicu D., Shparyk Y., 2004. Vegetation of the selected forest stands and land use in the Carpathian Mountains. Environmental Pollution 130:17-32. https://doi.org/10.1016/j.envpol.2003.10.031.

Guillot G., Mortier F., Estoup A., 2005. GENELAND : a computer package for landscape genetics. Molecular Ecology Notes 5:712-715. https://doi.org/10.1111/ j.1471-8286.2005.01031.x.

Guillot G., Renaud S., Ledevin R., Michaux J., Claude J., 2012. A unifying model for the analysis of phenotypic, genetic, and geographic data. Systematic biology 61:897-911. https://doi.org/10.1093/sysbio/sys038.

Gurung A.B., Bokwa A., Chełmicki W., Elbakidze M., Hirschmugl M., Hostert P., Ibisch P., Kozak J., Kuemmerle T., Matei E., Ostapowicz K., PociaskKarteczka J., Schmidt L., van der Linden S., Zebisch M., 2009. Global change research in the Carpathian Mountain Region. Mountain Research and Development 29:282-288. https://doi.org/10.1659/mrd.1105.

Hartl D.L., Grant A., 1997. Principles of population genetics. 3rd edn. Sinauer Associates Inc., Sunderland, MA, 545p. https://doi.org/10.2980/11956860(2007)14[544b:POPG]2.0.CO;2.

Jacob G., Debrunner R., Gugerli F., Schmid B., Bollmann K., 2010. Field surveys of capercaillie (Tetrao urogallus) in the Swiss Alps underestimated local abundance of the species as revealed by genetic analyses of non-invasive samples. Conservation Genetics 11:33-44. https://doi. org/10.1007/s10592-008-9794-8.

Janes J.K., Malenfant M., Andrew R.L., Miller J.M., Dupuis J.R., Gorrell J.C., Cullingham, C.I., 2017. The $\mathrm{K}=2$ conundrum. Molecular Ecology 26:3594-3602. https://doi.org/10.1111/mec.14187.

Keller L.F., Waller D.M 2002. Inbreeding effects in wild populations. Trends in Ecology and Evolution 17:230241. https://doi.org/10.1016/S0169-5347(02)02489-8.

Kimura M., Weiss, G., 1964. The stepping stone model of populationa structure and the decrease of genetic correlation with distance. Genetics 49(4):561-576.

Klinga P., Mikoláš M., Zhelev P., Höglund J., Paule, L., 2015. Genetic differentiation of western capercaillie in the Carpathian Mountains: The importance of post glacial expansions and habitat connectivity. Biological Journal of the Linnean Society 116:873-889. https:// doi.org/10.1111/bij.12643.

Lencinas M.V., Cellini J.M., Benitez J., Peri P.L., Martínez Pastur G., 2018. Variable retention forestry conserves habitat of bird species in Patagonian Nothofagus pumilio forests. Annals of Forest Research 61:147-160. https://doi.org/10.15287/afr.2018.1186.

Mäki-Petäys H., Corander J., Aalto J., Liukkonen T., Helle P., Orell M., 2007. No genetic evidence of sex-biased dispersal in a lekking bird, the capercaillie (Tetrao urogallus). Journal of evolutionary biology 20:865873. https://doi.org/10.1111/j.1420-9101.2007.01314.x.
Mikolas M., Svitok M., Tejkal M., Leitão P.J., Morrissey R.C., Svoboda M., Seedre M., Fontaine J.B., 2015. Evaluating forest management intensity on an umbrella species: Capercaillie persistence in central Europe. Forest Ecology and Management 354:26-34. https:// doi.org/10.1016/j.foreco.2015.07.001.

Mills L.S., Allendorf, F.W., 1996. The one-migrant-pergeneration rule in conservation and management. Conservation Biology 10:1509-1518. https://doi. org/10.1046/j.1523-1739.1996.10061509.x

Neville H.M., Isaak D.J., Dunham J.B., Thurow R.F., Rieman B.E., 2006. Fine-scale natal homing and localized movement as shaped by sex and spawning habitat in Chinook salmon: Insights from spatial autocorrelation analysis of individual genotypes. Molecular Ecology 15:4589-4602. https://doi. org/10.1111/j.1365-294X.2006.03082.x.

Peakall R., Smouse P.E., 2012. GenALEx 6.5: Genetic analysis in Excel. Population genetic software for teaching and research-an update. Bioinformatics 28:2537-2539. https://doi.org/10.1093/bioinformatics/ bts460.

Peakall R., Ruibal M., Lindenmayer D.B., 2003. Spatial autocorrelation analysis offers new insights into gene flow in the Australian bush rat, Rattus fuscipes. Evolution; international journal of organic evolution 57:1182-1195. https://doi. org/10.1111/j.0014-3820.2003.tb00327.x.

Piertney S.B., Hoglund J., 2001. Polymorphic microsatellite DNA markers in black grouse (Tetrao tetrix). Molecular Ecology Notes 1:303-304.

Piry S., Luikart G., Cornuet J.M., 1999. Computer note. BOTTLE- NECK: a computer program for detecting recent reductions in the effective size using allele frequency data. Journal of Heredity 90:502-503.

Pritchard J.K., Stephens M., Donnelly P., 2000. Inference of population structure using multilocus genotype data. Genetics 155:945-959. https://doi.org/10.1111/j.14718286.2007.01758.x.

Puechmaille S.J., 2016. The program STRUCTURE does not reliably recover the correct population structure when sampling is uneven: subsampling and new estimators alleviate the problem. Molecular Ecology Resources 16:608-627. https://doi.org/10.1111/17550998.12512.

Regnaut S., 2004., Population genetics of capercaillie (Tetrao urogallus) in the jura and the pyrenees : A noninvasive approach to avian conservation genetics. $\mathrm{PhD}$ thesis, UNIL/CHUV, Lausanne, 180p.

Regnaut S., Christe P., Chapuisat M., Fumagalli L., 2006. Genotyping faeces reveals facultative kin association on capercaillie's leks. Conservation Genetics 7:665674. https://doi.org/10.1007/s10592-005-9097-2.

Rodríguez-Muñoz R., Mirol P.M., Segelbacher G., Fernández A., Tregenza T., 2007. Genetic differentiation of an endangered capercaillie (Tetrao urogallus) population at the Southern edge of the species range. 
Conservation Genetics 8:659-670. https://oi. org/10.1007/s10592-006-9212-z.

Rösner S., Brandl R., Segelbacher G., Lorenc T., Müller J., 2014. Noninvasive genetic sampling allows estimation of capercaillie numbers and population structure in the Bohemian Forest. European Journal of Wildlife Research 60:789-801. https://doi.org/10.1007/s10344014-0848-6.

Rousset F., 1997. Genetic Differentiation and Estimation of Gene Flow from FStatistics Under Isolation by Distance. Genetics 145:1219-1228.

Rutkowski R., Niewęgłowski H., Dziedzic R., Kmieć M., Goździewski J., 2005. Genetic variability of Polish population of the Capercaillie Tetrao urogallus. Acta Ornithologica 40:27-34.

Segelbacher G., 2002. Genetic structure of capercaillie populations: a non-invasive approach at multiple spatial scales. $\mathrm{PhD}$ thesis, Technischen Universität München, Munchen, 98 p.

Segelbacher G., Piertney S., 2007. Phylogeography of the European capercaillie (Tetrao urogallus) and its implications for conservation. Journal of Ornithology 148:269-274. https://doi.org/10.1007/s10336-0070153-1.

Segelbacher G., Storch, I., 2002. Capercaillie in the Alps : genetic evidence of metapopulation. Molecular Ecology 11:1669-1677.

Segelbacher G., Paxton R., Steinbrueck G., Trontelj P., Storch I., 2000. Characterization of microsatellites in capercaillie Tetrao urogallus. Molecular Ecology 9:1934-1935.

Segelbacher G., Hoglund J., Storch I., 2003. From connectivity to isolation: genetic consequences of population fragmentation in capercaillie across Europe. Molecular Ecology 12:1773-1780. https://oi. org/10.1046/j.1365-294X.2003.01873.x.

Segelbacher G., Wegge P., Sivkov A. V., Höglund J., 2007. Kin groups in closely spaced capercaillie leks. Journal of Ornithology 148:79-84.https://doi.org/10.1007/ s10336-006-0103-3

Segelbacher G., Manel S., Tomiuk J., 2008. Temporal and spatial analyses disclose consequences of habitat fragmentation on the genetic diversity in capercaillie (Tetrao urogallus). Molecular ecology 17:2356-2367. https://doi.org/10.1111/j.1365-294X.2008.03767.x.

Slatkin M., 1985. Gene flow in natural populations. Annual review of ecology and systematics 16:393-430. https://doi.org/10.1146/annurev.ecolsys.16.1.393.

Smouse P.E., Peakall R., Gonzales E., 2008. A heterogeneity test for fine-scale genetic structure. Molecular Ecology 17:3389-3400. https://doi. org/10.1111/j.1365-294X.2008.03839.x.

Soulé M.E., 1987. Viable populations for conservation. Cambridge University Press, Cambridge, $185 \mathrm{p}$.

Storch I., 1993. Habitat selection by capercaillie in summer and autumn: is bilberry important? Oecologia 93:257-265.

Straupe I., Liepa L., ZaliteA.A., 2019. Habitat management for capercaillie Tetrao urogallus L. leks: The survey of vegetation changes. Research for Rural Development 1:38-43. https://doi.org/10.22616/rrd.25.2019.006.

Tallmon D.A., Luikart G., Waples R.S., 2004. The alluring simplicity and complex reality of genetic rescue. Trends in Ecology and Evolution 19:489-496. https://doi. org/10.1016/j.tree.2004.07.003.

Vallant S., Niederstätter H., Berger B., Lentner R., Parson, W., 2018. Increased DNA typing success for feces and feathers of capercaillie (Tetrao urogallus) and black grouse (Tetrao tetrix). Ecology and Evolution 8:39413951. https://doi.org/10.1002/ece3.3951.

Van Oosterhout C., Hutchinson W.F., Wills D.P.M., Shipley P., 2004. MICRO-CHECKER: Software for identifying and correcting genotyping errors in microsatellite data. Molecular Ecology Notes 4:535-538. https://doi. org/10.1111/j.1471-8286.2004.00684.x.

Wang J., 2004. Application of the one-migrant-pergeneration rule to conservation and management. Conservation Biology 18:332-343. 